\title{
Knowledge, attitude, practice, and self-efficacy of caregivers of children with epilepsy: impact of a structured educational intervention program
}

Mahmoud Abdel Hameed Shahin ${ }^{1}$, Rasha Mohammed Hussien ${ }^{2}$

${ }^{1}$ Al-Ghad International Colleges for Applied Medical Sciences, Qassim, Saudi Arabia

${ }^{2}$ Faculty of Nursing, Zagazig University, Zagazig, Egypt

Key words: Attitudes, Caregivers, Epilepsy, Knowledge, Practice, Self-efficacy

Received: June 28, 2020 ; Accepted: October 20, 2020

\section{Abstract}

Background: The parental role is crucial in the management of children with epilepsy before, during, and after the seizures. It is crucial to ascertain the sufficient knowledge, attitude, and proper practice of the caregivers about epilepsy; however, caregivers with high self-efficacy are more able to achieve caregiving tasks of epilepsy children at the best level.

Purpose: To assess the effect of an educational intervention on the knowledge, attitude, reported practice and self-efficacy of caregivers of children with epilepsy.

Methods: A pretest-posttest quasi-experimental design was used to carry out the study, in which a convenient sample of 60 caregivers for epilepsy children was chosen from the outpatient clinics of Al-Ahrar Zagazig Teaching Hospital. The candidates were asked to fill up a questionnaire as a pretest, and then were exposed to a tailored educational intervention about epilepsy before being reassessed again using the same questionnaire.

Results: Most of caregivers were married females, and mainly mothers. Although car egivers generally had low level of knowledge, attitudes, reported practices, and self-efficacy about epilepsy before the educational intervention, they improved significantly after the educational intervention. The educational program was a significant independent positive predictor of caregivers' scores of knowledge, attitudes, practice and self-efficacy.

Discussion: The study findings demonstrate significant improvements in the knowledge, attitude, and reported practice as well as the self-efficacy scores of caregivers of children with epilepsy following the implementation of the educational intervention, which reflects the importance of providing educational intervention to improve the knowledge, attitude, practice, and self-efficacy of epilepsy children caregivers. 


\section{Introduction}

Epilepsy is a prevalent neurological disorder characterized by recurrent seizures or convulsions unprovoked by immediate central nervous insult [1]. It is a common chronic neurological condition affecting at least 50 million people worldwide, with 10.5 million children under age 15 years being affected by active epilepsy [2]. In Egypt, the overall prevalence of epilepsy was $6.98 / 1000$ in 2016 [3]. The prevalence varies between 7.2/1000 in lower Egypt [4] and 9.7/1000 in upper Egypt [5].

Parents are mostly the primary caregivers of children with epilepsy. Caring for a child with a chronic life-threatening illness such as epilepsy carries major physical and psychological burdens on the parents [6].Those parents face a number of challenges including the stigma of disclosure of epilepsy, in addition to the lack of sound information about how to cope with the problem, and hence need psychosocial and emotional support [7, 8]. Moreover, research revealed that the quality of life of the parents providing care to their children with epilepsy is markedly compromised, which is subsequently reflected negatively on the management of the children's condition $[9,10]$. Added to these challenges is the substantial economic burden posed on the parents in terms of healthcare expenditure, in addition to loss of productivity at work leading to income losses [11].

The parental role is crucial in the management of child's seizures before, during, and after the seizures. They also have an important role in the process of decision-making about the choice of treatment modality for their children, and in the planning of a holistic care for them encompassing all social and psychological aspects [12]. In order to be able to fulfil these roles effectively, caregiving parents need to know the etiology of the disease and its effect on the child as well as the caregiver him/herself [13, 14]. This would also enhance their self-efficacy in dealing with their children's illness, which is a key element in Bandura's social cognitive theory [15]. In fact, the caregivers with high selfefficacy are more able to achieve caregiving tasks at the best level, with less psycho-social stress, fatigue, and tension [16]. However, parents' learning needs are often not fulfilled [17].

Epilepsy is a common problem in childhood with high burden on caregivers given the unpredictable seizures, and associated comorbid conditions. Education and training are essential in helping these caregivers to cope with the situation and provide good caregiving through improving their knowledge, attitude, skills, and self-efficacy.

\section{Methods}

This study was conducted to assess the effect of an educational intervention on the knowledge, attitude, reported practice and self-efficacy of caregivers of children with epilepsy. The research hypothesis was that the scores of caregivers' knowledge, attitude, reported practice and self-efficacy will significantly increase after implementation of the educational intervention.

\section{Research design and setting}

A one-group quasi-experimental pretestposttest design was used in carrying out the study at the pediatrics outpatient clinics affiliated to Al-Ahrar Zagazig Teaching Hospital. Al-Ahrar Hospital is an educational, public, tertiary healthcare facility with a capacity of 353 beds, and contains a huge outpatient de- 
partment that covers most specialty clinics. The hospital serves a large sector of people from various socio-economic and educational levels, who come from many villages surrounding the city of Zagazig. The selection of the city and the health care facility was associated with the convenience to researchers and the feasibility and accessibility of data collection.

\section{Subjects}

A non-random sampling technique was used to choose the study sample: the study was carried out on a convenience sample of 60 caregivers accompanying their children with epilepsy and receiving treatment in the study settings. The inclusion criteria were caregivers who accepted to participate, were able to read and write Arabic, were the primary caregivers of a children with epilepsy for at least one year and under treatment in the study settings. Seventy-seven caregivers met the inclusion criteria at the time of study implementation, 8 of whom declined to participate in the study due to personal reasons, 6 were excluded as they were involved in the piloting of the study questionnaire, and only three participants withdrew during the course of study implementation which reflected a response rate as high as $95 \%$. Considering the pretest and posttest groups, the sample size was calculated to demonstrate an improvement in mean knowledge/ practice/ attitudes/ and self-efficacy scores of at least 2.0 points with 3.0 standard deviation, at $95 \%$ level of confidence and $90 \%$ power. Using the OpenEpi software package, the required sample size was 48 subjects [18]. However, the number of participants was 60 which gives more power and reliability to the study findings.

\section{Data collection tool}

A structured self-administered questionnaire sheet was used to assess caregiver's knowledge, attitudes, practice and selfefficacy in the management of epilepsy before and after the intervention. It was developed by the researchers based on review of pertinent literature [19-29]. It was originally in English language, and was translated into simple Arabic language to be suitable for caregivers. It comprised six parts. The first part was for caregiver socio-demographic characteristics such as age, gender, educational level, and job status. The second part covered the bio-data of the child with epilepsy as well the detailed medical history of epilepsy including onset, duration, frequency, aura, treatment, in addition to history of other co-morbidities. The third part was for assessing caregivers' knowledge of epilepsy. It comprised 50 True/False questions covering five main areas. The first area was about the concepts and beliefs regarding epilepsy, with 6 items such as association with mental retardation, and autism, and considering the affected child as abnormal. The second area was about the nature and etiology of epilepsy, with 8 items such as changes in brain electricity, heredity, etc. The third area addressed the epileptic seizure through 15 items such as timing of the seizure, precipitating factors, duration, associated symptoms and signs. The fourth area covered treatment with 16 items including types of medications, indications, effectiveness, and duration of use. The fifth area was for safety measures during seizure with 5 items including preventive measures during seizure and other precautions in daily life. For scoring, a correct answer was scored " 1 " and an incorrect " 0 ". The total score of each area and for the total knowledge scale 
was calculated by simple summation. The maximum attainable score for each area was equal to the number of its items, and the maximum attainable total score was 50. A higher score indicates better knowledge. The fourth part of the questionnaire measured caregiver's attitude. It consisted of a scale with 15 items assessing caregiver's attitude towards the sporting or social activities of the child with epilepsy, difference from siblings, stopping child medication, belief in herbal remedies, magic and religious practices to treat epilepsy. The response to each item was on a 3-point Likert scale "agree, uncertain, and disagree," scored respectively from 3 to 1 . Scoring was reversed for negative items so that a higher score indicates a more positive attitude. The maximum total attainable score was 15.The fifth part of the questionnaire was intended to assess caregiver's reported practice while caring for the child with epilepsy. It comprised 18 questions with sub-items categorized into practices during seizure (11 items including turning child head to one side, and avoiding forceful restriction), after seizure ( 5 items with sub-items including giving child time to rest, and avoid anything by mouth till fully conscious), seeking help (2 questions with sub-items including seeking help if seizures lasts $>5 \mathrm{~min}$, and if child is injured during seizure). For scoring, a correct answer was scored " 1 " and an incorrect " 0 ". The total score of each area and for the total scale was calculated by simple summation. The maximum attainable score was 25.The sixth part of the tool measured caregiver's self-efficacy using the "Revised Scale for Caregiving Self-Efficacy" developed by Steffen et al. [19]. It consisted of 3 subscales. The first measured self-efficacy in getting respite with five items such as asking help from friend/family for doctor visit and for one day caring of your child. The second subscale measured self-efficacy in responding to the disruptive behavior of the sick child, with five items such as avoiding yelling at child while asking repeatedly for something or interrupting, etc. The third subscale was for self -efficacy to control upsetting thoughts about caregiving, with five items such as ability to control thinking about negative sides of child illness and losses. The response to each item was on a 3-point Likert scale "agree, uncertain, and disagree." These were scored respectively from 3 to 1 . The total score of each subscale and for the total scale was calculated by simple summation so that a higher score indicates higher self-efficacy. The maximum attainable score was 45. Revised Scale for Caregiving Self-Efficacy (RSCSE) validity and reliability were tested and approved in a recent cross-national review in different languages conducted to validate the RSCSE[30].

\section{Quality of data collection tool}

Piloting of the questionnaire was carried out in 6 caregivers of children with epilepsy who fulfilled the inclusion criteria, to test the feasibility, clarity, and reliability of the scales and to find out the time required to complete the questionnaire. No changes were made based on the piloting, but the questionnaires of the piloting were excluded from analysis. The questionnaire was designed in a selfexplanatory, simple language, which allows the caregivers to fill it up in 25-30 minutes at most. Translation and reverse translation of the questionnaire were carried out and compared before being submitted for validity and reliability testing. The content validity of the Arabic translated questionnaire was executed by consulting three experts in neuro, commu- 
nity, and psychiatric health nursing and deemed valid. The test-retest reliability of the questionnaire was conducted and revealed acceptable reliability in all scales, with Cronbach's alpha of 0.801 for knowledge scale, 0.832 for attitudes scale, 0.813 for practice scale, and 0.854 for self-efficacy scale.

\section{Study maneuver}

The study was achieved through assessment, planning, implementation, and evaluation phases. The fieldwork lasted approximately 3 months from the first of January 2020 to the end of March, 2020.Assessment phase: During this phase, the researchers started the recruitment process. They met with the caregivers in the study settings to explain the aim of the study and its procedures and to obtain their informed consent to participate. Those who agreed to participate were given the questionnaire form and instructions in filling it. This served as a baseline for comparison with the posttest and helped the researchers to identify caregivers' learning needs in order to prepare the intervention accordingly. The caregivers filled the forms on-site and the researchers were present during the whole process to clarify any ambiguities, and to collect the completed forms.

Planning phase: The researchers analyzed the pretest data obtained in the assessment phase to guide in the preparation of the intervention. The intervention goal, specific objectives, and time schedule were developed accordingly, and the teaching methods were selected. The researchers also prepared a handbook entitled "A counselling program for the caregiver of a child with epilepsy to help improve practices and self-efficacy" in simple Arabic language to suit the level of the attending caregivers. This 30-page booklet was developed after reviewing the related and updated literature $[31,32]$. Moreover, the content of the booklet was chosen based on the identified needs of the caregivers. The booklet covered a variety of information of significant importance to caregivers of children with epilepsy, including the definitions, causes, and hazards of epilepsy; types and signs and symptoms of epilepsy; diagnosis of epilepsy; treatment, medicines, and side effects; nutrition, sleep, rest and exercise needs of the children; instructions about the protection during epilepsy; in addition to the first aid and recovery position training.

Implementation phase: The participating caregivers were divided into small groups of 5 members each for administration of the intervention. The researchers explained the purpose of the study, as well as the intervention content and procedure of training. Each participant received a copy of the prepared booklet. The educational program consisted of four sessions (90 minutes each), repeated for each group of caregivers. Different teaching media were used, including PowerPoint presentations, illustrative pictures, posters, and related videos. The training followed the adult learning principles with emphasis on group discussions and active participation. Those educational sessions were carried out during the morning shift in a special education room in the outpatient department of the hospital. The duration of the full program for each group was 6 hours. Motivation and reinforcement techniques were used to enhance caregivers' active participation and to foster their learning and education process.

Evaluation phase: The effect of the teaching intervention on participants' knowledge, 
attitudes, practice, and self-efficacy was assessed through an immediate posttest after completion of the program using the same questionnaire of the pretest. The questionnaires were collected by the researchers upon completion.

\section{Statistical Analysis}

Data were collected, revised, coded, and entered using personal computer (PC). Statistical analysis was carried out using the Statistical Package for Social Sciences (SPSS) version 25. Data were presented using descrip-

Table 1. Demographic characteristics of caregivers of children with epilepsy $(n=60)$

\begin{tabular}{|c|c|c|}
\hline Characteristics & $\mathbf{n}$ & $\%$ \\
\hline \multicolumn{3}{|l|}{ Age: } \\
\hline $19-<30$ & 24 & 40.0 \\
\hline $30-<40$ & 26 & 43.3 \\
\hline $40-50$ & 10 & 16.7 \\
\hline Mean \pm SD & \multicolumn{2}{|c|}{$31.3 \pm 11.9$} \\
\hline \multicolumn{3}{|l|}{ Gender: } \\
\hline Male (father) & 8 & 13.3 \\
\hline Female (mother) & 52 & 86.7 \\
\hline \multicolumn{3}{|l|}{ Education: } \\
\hline No, read and write & 7 & 11.7 \\
\hline Primary & 14 & 23.3 \\
\hline Secondary & 29 & 48.3 \\
\hline University & 10 & 16.7 \\
\hline \multicolumn{3}{|l|}{ Marital status: } \\
\hline Married & 50 & 83.3 \\
\hline Divorced/widow & 10 & 16.7 \\
\hline \multicolumn{3}{|l|}{ Job status: } \\
\hline Working & 15 & 25.0 \\
\hline Not working & 45 & 75.0 \\
\hline \multicolumn{3}{|l|}{ Residence: } \\
\hline Rural & 26 & 43.3 \\
\hline Urban & 34 & 56.7 \\
\hline \multicolumn{3}{|l|}{ Income: } \\
\hline Sufficient & 20 & 33.3 \\
\hline Insufficient & 40 & 66.7 \\
\hline $\begin{array}{l}\text { Had training in caring for } \\
\text { child with epilepsy }\end{array}$ & 6 & 10.0 \\
\hline $\begin{array}{l}\text { Had experience in caring for } \\
\text { child with epilepsy }\end{array}$ & 7 & 11.7 \\
\hline
\end{tabular}

tive statistics in the form of mean and standard deviation or number and percentage. The paired t-test was used to determine the means significance difference between two groups (significant at $\mathrm{p}<0.05$ ). The linear regression model was used to model the relationship between a scalar response and one or more explanatory variables; however, it was used to detect the independent predictors of caregivers' scores of knowledge, attitudes, practice, and self-efficacy (significant at $\mathrm{p}<0.05$, and highly significant at $<0.01$ ).

\section{Ethical considerations}

Before embarking on the study, a permission letter was granted from the administration of Al-Ahrar Teaching Hospital after having been fully informed about the purpose of the study and its procedures. The researchers complied with all research ethics principles according to the Helsinki Declaration. Caregivers were informed that their participation in the study was totally voluntary, with no consequences if they chose not to participate or to withdraw at any time. The confidentiality and anonymity of any information obtained were ensured, and codes were given to the questionnaires returned. Written informed consent was signed by each participant to fill the questionnaire. No further risk was expected due to the participation of the caregivers in the current study.

\section{Results}

The caregivers in the study sample were mostly mothers $(86.7 \%)$, with a mean age of 31.3 years as shown in Table 1. Only $11.7 \%$ were able to read and write without formal education, while almost half of them had secondary education (48.3\%). The majority were married $(83.8 \%)$, not working $(75.0 \%)$, and 
Table 2. Demographic characteristics and medical history of children with epilepsy $(\mathrm{n}=60)$

\begin{tabular}{|c|c|c|}
\hline Sociodemographic characteristics & $\mathrm{n}$ & $\%$ \\
\hline \multicolumn{3}{|l|}{ Age (years): } \\
\hline$<4$ & 34 & 56.7 \\
\hline $4-<8$ & 14 & 23.3 \\
\hline $8-12$ & 12 & 20.0 \\
\hline Mean \pm SD & \multicolumn{2}{|c|}{$5.8 \pm 2.4$} \\
\hline \multicolumn{3}{|l|}{ Gender: } \\
\hline Male & 22 & 36.7 \\
\hline Female & 38 & 63.3 \\
\hline \multicolumn{3}{|l|}{ Birth order: } \\
\hline First & 13 & 21.7 \\
\hline Second & 28 & 46.7 \\
\hline Third & 19 & 31.6 \\
\hline \multicolumn{3}{|l|}{ Number of siblings: } \\
\hline $1-2$ & 27 & 45.0 \\
\hline $3-5$ & 33 & 55.0 \\
\hline Mean \pm SD & \multicolumn{2}{|c|}{$2.7 \pm 1.9$} \\
\hline Epilepsy features, medical history & $\mathrm{n}$ & $\%$ \\
\hline \multicolumn{3}{|l|}{ Duration (years): } \\
\hline$<4$ & 36 & 60.0 \\
\hline $4-<8$ & 16 & 26.7 \\
\hline $8-12$ & 8 & 13.3 \\
\hline \multicolumn{3}{|l|}{ Frequency of seizures/month: } \\
\hline $1-2$ & 11 & 18.3 \\
\hline $3-5$ & 49 & 81.7 \\
\hline \multicolumn{3}{|l|}{ Duration of seizures (minutes): } \\
\hline $1-2$ & 23 & 43.3 \\
\hline $3-5$ & 37 & 61.7 \\
\hline Seizures preceded by precipitating factors & 43 & 71.7 \\
\hline Child has aura before seizure & 29 & 48.3 \\
\hline Compliant with treatment & 22 & 36.7 \\
\hline \multicolumn{3}{|l|}{ Effect of treatment: } \\
\hline Improved & 20 & 33.0 \\
\hline Same & 35 & 59.0 \\
\hline Worse & 5 & 8.0 \\
\hline Child has other chronic diseases & 10 & 16.7 \\
\hline Medication for chronic disease & 9 & 90.0 \\
\hline \multicolumn{3}{|l|}{ Epilepsy affected relationship: } \\
\hline Within family & 11 & 18.3 \\
\hline Outside family & 47 & 78.3 \\
\hline
\end{tabular}

$\mathrm{n}=$ frequency, $\%=$ percent, $\mathrm{SD}=$ standard deviation

with insufficient income (66.7\%). Slightly more than a half of them were residing in urban areas (56.7\%). Only very few of them reported previous training in caring for a child with epilepsy $(10 \%)$, or had previous experience in it $(11.7 \%)$.
As for the children with epilepsy, Table 2 indicates that most of them were aged below four years $(56.7 \%)$, with approximately twothirds of them being females (63.3\%). Most of these children were second in birth order (46.7\%), and had 3-5 siblings (55.0\%). In approximately two-thirds of the children in the study sample, the duration of epilepsy was less than four years $(60.0 \%)$. The seizures mostly occurred 3-5 times per month (81.7\%) and lasted 3-5 minutes (61.7\%), preceded by precipitating factors $(71.7 \%)$. Only $36.7 \%$ of the children were compliant with treatment, and an almost equal percentage $(33.0 \%)$ improved on treatment. Epilepsy had less negative impact on the relationship within the family of the affected child (18.3\%) than on the family relationship with the outside community $(78.3 \%)$.

Table 3 reveals generally low scores of caregivers' knowledge, attitudes, and reported practices in all the tested areas in the preintervention phase. The mean score of knowledge at the pre-intervention phase (23.65) was less than half of the maximum attainable score of 50.0. The postintervention scores of knowledge, attitude, and reported practice demonstrated statistically significant improvements $(p<0.001)$. This was observed in all areas as well as in total scores. The mean total scores of knowledge and practice almost doubled $(p<$ 0.001 ).

As displayed in Table 4, low scores were noted in all three aspects of self-efficacy as well as in total before the intervention, with the total mean score being less than a half of the maximum attainable score of 45.0. Meanwhile, statistically significant improvements were shown at the post-intervention phase in all areas of self-efficacy. The mean total 
Table 3. Knowledge, attitude, and reported practice of car egivers of children with epilepsy pre- and post-intervention

\begin{tabular}{|c|c|c|c|c|}
\hline & \multicolumn{2}{|c|}{ Score $($ mean \pm SD) } & \multirow{2}{*}{$\begin{array}{c}\text { Paired } \\
\text { t-test }\end{array}$} & \multirow{2}{*}{ p value } \\
\hline & Pre $(\mathrm{N}=60)$ & Post $(\mathrm{N}=60)$ & & \\
\hline \multicolumn{5}{|l|}{ Knowledge: } \\
\hline Concept of epilepsy $(\max =6)$ & $2.79 \pm 1.14$ & $4.88 \pm 1.22$ & 10.678 & $0.000^{* *}$ \\
\hline Nature of epilepsy $(\max =8)$ & $3.69 \pm 2.30$ & $6.09 \pm 2.06$ & 12.258 & $0.000^{* *}$ \\
\hline Epileptic seizure $(\max =15)$ & $6.38 \pm 2.49$ & $12.57 \pm 4.13$ & 13.487 & $0.001 * *$ \\
\hline Medical treatment $(\max =16)$ & $7.08 \pm 3.68$ & $13.03 \pm 3.67$ & 11.915 & $0.000^{* *}$ \\
\hline Safety measures $(\max =5)$ & $2.00 \pm 0.94$ & $3.26 \pm 1.01$ & 6.553 & $0.000^{* *}$ \\
\hline Total knowledge $(\max =50)$ & $23.65 \pm 9.37$ & $41.07 \pm 8.23$ & 15.351 & $0.000 * *$ \\
\hline \multicolumn{5}{|l|}{ Attitude: } \\
\hline $\begin{array}{l}\text { Epilepsy is not an obstacle to a child's sporting or social } \\
\text { activities }(\max =3)\end{array}$ & $1.57 \pm 0.49$ & $2.46 \pm 0.67$ & 6.452 & $0.001 * *$ \\
\hline $\begin{array}{l}\text { Dealing with a child with epilepsy is not different from } \\
\text { his/her siblings }(\max =3)\end{array}$ & $1.38 \pm 0.55$ & $2.63 \pm 0.81$ & 9.32 & $0.000^{* *}$ \\
\hline $\begin{array}{l}\text { I would not stop giving my child medication when the } \\
\text { seizures have stopped for several months }(\max =3)\end{array}$ & $2.01 \pm 0.23$ & $2.84 \pm 0.60$ & 8.707 & $0.000^{* *}$ \\
\hline $\begin{array}{l}\text { I don't believe herbal remedies may be used in addition } \\
\text { to the treatment prescribed by doctor }(\max =3)\end{array}$ & $1.42 \pm 0.71$ & $2.39 \pm 0.74$ & 11.32 & $0.001 * *$ \\
\hline $\begin{array}{l}\text { Epilepsy cannot be treated with magic and religious } \\
\text { practices }(\max =3)\end{array}$ & $1.88 \pm 0.59$ & $2.76 \pm 0.58$ & 10.264 & $0.000^{* *}$ \\
\hline Total attitude $(\max =15)$ & $8.26 \pm 1.15$ & $13.08 \pm 1.52$ & 19.588 & $0.001 * *$ \\
\hline \multicolumn{5}{|l|}{ Reported practice: } \\
\hline Practices during seizure $(\max =11)$ & $5.26 \pm 3.06$ & $9.57 \pm 2.18$ & 13.6 & $0.001 * *$ \\
\hline Practices after seizure $(\max =5)$ & $2.89 \pm 1.91$ & $4.70 \pm 2.11$ & 9.01 & $0.005^{* *}$ \\
\hline Seeking help $(\max =9)$ & $3.08 \pm 1.35$ & $7.99 \pm 1.13$ & 10.2 & $0.003^{* *}$ \\
\hline Total $(\max =25)$ & $11.37 \pm 5.46$ & $20.41 \pm 4.23$ & 16.63 & $0.001 * *$ \\
\hline
\end{tabular}

**Significant at the 0.01 level (2-tailed)

Table 4. Caregivers' self-efficacy in caring for children with epilepsy pre- and postintervention

\begin{tabular}{|c|c|c|c|c|}
\hline \multirow{2}{*}{ Self-efficacy } & \multicolumn{2}{|c|}{ Score $($ mean \pm SD) } & \multirow{2}{*}{$\begin{array}{c}\text { Paired } \\
\text { t-test }\end{array}$} & \multirow{2}{*}{ p value } \\
\hline & Pre $(n=60)$ & Post $(n=60)$ & & \\
\hline \multicolumn{5}{|l|}{ Self-efficacy to: } \\
\hline Obtain respite $(\max =15)$ & $7.59 \pm 3.38$ & $9.51 \pm 4.38$ & 8.31 & $0.011 *$ \\
\hline Respond to child disruptive behavior $(\max =15)$ & $6.99 \pm 4.16$ & $11.67 \pm 3.81$ & 12.24 & $0.001 * *$ \\
\hline Control Upsetting Thoughts about care $(\max =15)$ & $8.01 \pm 3.81$ & $12.33 \pm 3.42$ & 11.9 & $0.002 * *$ \\
\hline Total $(\max =45)$ & $22.08 \pm 7.46$ & $34.20 \pm 6.08$ & 15.64 & $0.001 * *$ \\
\hline
\end{tabular}

**Significant at the 0.01 level (2-tailed). *Significant at the 0.05 level (2-tailed)

score increased from 22.08 to 34.20 ( $p<$ $0.001)$.

In a multivariate analysis (Table 5), the training program was identified as the main statistically significant independent positive predictor for the scores of attitudes and reported practice, as indicated by the standard- ized partial regression coefficients. For the knowledge score, the main positive predictors were the duration of illness and the caregiver's educational level, with less influence of the training program. Other significant independent positive predictors of the three scores were older age of caregivers, higher 
Table 5. Best fitting multiple linear regression model for caregivers' knowledge, attitude, and reported practice scores

\begin{tabular}{|c|c|c|c|c|c|}
\hline & \multicolumn{2}{|c|}{ Unstandardized coefficients } & \multirow{2}{*}{$\begin{array}{l}\text { Standardized partial } \\
\text { regression coefficients }\end{array}$} & \multirow{2}{*}{ t-test } & \multirow{2}{*}{ p-value } \\
\hline & B & Std. Error & & & \\
\hline \multicolumn{6}{|c|}{ Knowledge } \\
\hline Duration of illness & 0.678 & 0.647 & 0.114 & 21.546 & $0.001 * *$ \\
\hline Educational level & 0.741 & 0.114 & 0.110 & 11.023 & $0.021 *$ \\
\hline Previous experience in caring & 0.759 & 0.441 & 0.087 & 19.006 & $0.001 * *$ \\
\hline Caregiver age & 0.638 & 0.26 & 0.054 & 13.482 & $0.014^{*}$ \\
\hline Training program & 0.931 & 0.015 & 0.054 & 16.334 & $0.001 * *$ \\
\hline \multirow{2}{*}{\multicolumn{6}{|c|}{$\begin{array}{c}\text { Variables entered and excluded: job status } \\
\text { Attitude }\end{array}$}} \\
\hline & & & & & \\
\hline Training program & 0.841 & 0.547 & 0.314 & 18.331 & $0.001 * *$ \\
\hline Educational level & 0.763 & 0.163 & 0.201 & 13.023 & $0.007 * *$ \\
\hline Experience in caring & 0.812 & 0.309 & 0.069 & 17.31 & $0.002 * *$ \\
\hline Caregiver age & 0.566 & 0.168 & 0.064 & 9.022 & $0.016^{*}$ \\
\hline Knowledge score & 0.918 & 0.031 & 0.059 & 19.531 & $0.001 * *$ \\
\hline Duration of illness & 0.567 & 0.32 & 0.012 & 13.055 & $0.004 * *$ \\
\hline r-square $=0.80$ & \multicolumn{5}{|c|}{ Variables entered and excluded: job status } \\
\hline \multicolumn{6}{|c|}{ Reported practice } \\
\hline Training program & 0.997 & 0.039 & 0.238 & 13.009 & $0.003 * *$ \\
\hline Educational level & 0.852 & 0.276 & 0.189 & 16.143 & $0.001 * *$ \\
\hline Duration of illness & 0.667 & 0.097 & 0.123 & 10.138 & $0.008 * *$ \\
\hline Previous experience in caring & 0.886 & 0.435 & 0.057 & 12.201 & $0.005 * *$ \\
\hline Self-efficacy score & 0.591 & 0.061 & 0.047 & 9.112 & $0.009 * *$ \\
\hline Caregiver age & 0.587 & 0.143 & 0.036 & 7.515 & $0.023 *$ \\
\hline r-square $=0.66$ & \multicolumn{5}{|c|}{ Variables entered and excluded: job status } \\
\hline
\end{tabular}

Table 6. Best fitting multiple linear regression model for the self-efficacy score

\begin{tabular}{|c|c|c|c|c|c|}
\hline & \multicolumn{2}{|c|}{ Unstandardized coefficient } & \multirow{2}{*}{$\begin{array}{l}\text { Standardized partial } \\
\text { regression coefficient }\end{array}$} & \multirow{2}{*}{ t-test } & \multirow{2}{*}{ p-value } \\
\hline & B & Std. Error & & & \\
\hline Training program & 0.975 & 0.432 & 0.237 & 13.553 & $0.003 * *$ \\
\hline Educational level & 0.864 & 0.237 & 0.103 & 12.104 & $0.005 * *$ \\
\hline Practice score & 1.235 & 0.309 & 0.074 & 17.668 & $0.001 * *$ \\
\hline Age & 0.794 & 0.157 & 0.066 & 9.687 & $0.008 * *$ \\
\hline Previous experience in caring & 0.794 & 0.314 & 0.058 & 15.268 & $0.002 * *$ \\
\hline Duration of illness & 0.436 & 0.244 & 0.026 & 6.055 & $0.012 *$ \\
\hline r-square $=0.78$ & \multicolumn{5}{|c|}{ Variables entered and excluded: job status } \\
\hline
\end{tabular}

**Significant at the 0.01 level (2-tailed). *Significant at the 0.05 level (2-tailed)

educational level, previous experience in caring for an epileptic child, and longer duration of epilepsy illness. Moreover, self-efficacy was a positive predictor of the reported prac- tice score. On the other hand, job status had no significant influence on any of these scores. The models explain respectively $83 \%$, $80 \%$, and $66 \%$ of the variations in 
knowledge, attitude and reported practice scores.

Similarly, Table 6 illustrates that the training program, as well as, the caregiver's higher educational level, higher reported practice score, older age, previous experience in caring for an epileptic child, and longer duration of epilepsy illness were statistically significant independent positive predictors of the self-efficacy score. Meanwhile, job status had no significant influence on it. The model explains $78 \%$ of the variation in the practice score. As the standardized partial regression coefficients reveal, the training program and the level of education were the most influential on the self-efficacy score.

\section{Discussion}

The study findings demonstrate significant improvements in the knowledge, attitude, and reported practice as well as the self-efficacy scores of caregivers of children with epilepsy following implementation of the educational intervention. The findings lead to acceptance of the set research hypothesis, and thus the study achieved its main objectives.

The characteristics of the present study sample of caregivers indicate their representativeness of the Egyptian attendants of governmental hospitals. They were mostly unemployed women, with insufficient income, and low level of education. This would add to the external validity of the study, with better ability to generalize its findings. Moreover, these caregivers' characteristics were shown to have significant influences on caregivers' knowledge, attitude, reported practice, and self-efficacy.

According to the current study results, a great majority of the caregivers in the study sample were the mothers of epileptic chil- dren. Such a high percentage of female caregivers is consistent with the known women nature, which makes them take the major responsibility of caring for their ill relatives. In agreement with this, Hamaad and Alseraty [33] in a study in Egypt reported that the highest percentage of caregivers of children with epilepsy were females.

The present study revealed a marked deficiency in caregivers' knowledge of epilepsy. This was particularly evident regarding the area of medical treatment. The finding might be explained by the generally low level of education in the study sample, and the related misconceptions regarding medical treatment issues such as stopping medications when there are no seizures. In congruence with this, a study in the United States reported that the majority of the parents of children with epilepsy in the sample were having deficient knowledge of the definition and nature of epilepsy and its seizures [34]. Similar findings were also reported by Masri et al. [35] in a study carried out in Jordan.

The implementation of the training program in the present study led to significant improvements in all knowledge areas. However, in the multivariate analysis, the main factors independently and significantly influencing the post-intervention knowledge score were the duration of child illness and the educational level of the caregiver, while the training program had a positive but less important influence. This indicates that the caregivers may accumulate knowledge along the child's illness trajectory, and this increases with the duration of illness. In line with this, a study in Turkey reported a significant correlation between parents' educational level and their knowledge about epilepsy [36]. Moreover, another study in Turkey revealed signifi- 
cant improvements in the knowledge of mothers of children with epilepsy following the implementation of an educational program [37].

Concerning caregivers' attitude, the current study demonstrated generally low preintervention scores, indicating a tendency towards negative attitude. This could be attributed to the prevailing low socio-economic level in the study sample, which would increase the caregivers' negative feelings towards epilepsy, considering it a shame or stigma that needs to be hidden, in addition to other related misconceptions. The findings are in agreement with Rani and Thomas [38] whose study in India revealed negative parents' attitudes towards their epilepsy that affected their children, attributing it to evil spirits and thus tending to use religious and spiritual approaches to treatment.

In the post-intervention phase, the caregivers' scores showed significant improvements in all aspects. This was mainly due to the effect of the training program as revealed in the multivariate analysis. The positive impact of the program on the caregivers could be attributed to the correction of the misconceptions related to epilepsy. This was fostered by the interactive process of the training, which helped attendants to openly discuss and ventilate all their concerns and queries about the illness. In congruence with this, a study in Malaysia applied an educational program to improve the knowledge, attitude, and awareness of epilepsy children's parents showed significant improvements in their attitudes, with a majority shifting from negative to positive attitudes [39].

The present study findings demonstrated that the practices of the caregivers were low in all three aspects, namely before, during, and after seizure, as well as in seeking help. These results are alarming since the caregiver's practice during these critical times is crucial in saving the child from complications that could be fatal. This could be attributed to the lack of training in caring for a child with epilepsy, as only about $10 \%$ of them reported having had such training. In agreement with this, Hamaad and Alseraty [33] in a study in Egypt reported mostly inadequate caregivers' practices in dealing with children with epileptic seizures, and most of them reported that they would prefer to avoid dealing with these children. Along the same line, a study in Central Uganda found that caregivers' lack of knowledge and training was the main barrier in the care for epilepsy [40].

The implementation of the training led to significant improvements in the current study caregivers' reported practice. In fact, the training was the main independent predictor of the reported practice score. The findings underscore the value of training in improving caregivers' practice. The success of the training program in improving caregivers' practice results might be attributed to the strong desire of the participants to receive the needed information about their children's illness to be able to handle any related problems. In line with this, Mousavi Dogahe et al. [41] in a study in Iran reported that an educational program on the care for sick children was successful in improving mothers' practice after the intervention. Similarly, a study in the United States showed the effectiveness of caregivers' training intervention in improving their practices in caring for patients with epilepsy [42].

Similarly, the current study results showed that the caregivers of epileptic children were having low self-efficacy in dealing with the 
sick child. This was evident in all its three areas, particularly in dealing with child' disruptive behavior. This again could be due to the lack of training and experience in caring for the epileptic child. It could also be attributed to the generally low level of education among them. In fact, the level of education was identified as a significant independent positive predictor of the self-efficacy score. Such low self-efficacy in dealing with the child would negatively affect the caregiver's psychological wellbeing, with a consequent negative impact on the epileptic child. In congruence with this, a study in Canada revealed that improving caregivers' psychological wellbeing improved the prognosis of children with epilepsy[10].

In the post-intervention phase, significant improvements were shown in caregivers' scores of self-efficacy. Thus, the implementation of the training led to such improvement of the self-efficacy score, that it was revealed to be a significant independent positive predictor by multivariate analysis. The effectiveness of the training could be credited to the content and process of the training, which responded to identified caregivers' needs, and allowed their active participation in the training process. In agreement with this, a study in the United States demonstrated that a nurseled training program was successful in improving caregivers' self-efficacy [43]. At the same line, Tan et al. [44] in a study in Malaysia demonstrated that caregivers' self-efficacy was significantly improved by training.

The present study results have also revealed a mutually positive relation between caregivers' practice and self-efficacy. This was shown in the regression analyses. Thus, the improved practice would lead to greater self-efficacy, and reciprocally higher self- efficacy would lead to better practice. In congruence with this, Gholami et al. [45] in a study in Iran showed that a supportive educational program promoting self-efficacy improved mothers' care of children with epilepsy and the measures taken in the emergency stages of epilepsy. Moreover, a study in Japan demonstrated a significant positive correlation between caregivers' performance and self-efficacy scores [46].

\section{Recommendations and limitations}

Further research are proposed to test the effectiveness of the intervention in a completely randomized clinical trial design for more robust evidence. To assure the sustainability of the educational intervention effect, it is recommended to make reassessment over a long-time plan utilizing the time series design. On the other hand, random sampling constitutes one of the major threats and limitations to the study findings. Therefore, it is recommended to implement the study on random caregiver samples with the inclusion of hospitals from other governorates in Egypt. In addition, the use of self-reporting questionnaires is one of the limitations of the study as it is preferable to use an evaluation method by direct observation in assessing the attitudes and practices of caregivers of children with epilepsy during epileptic seizures and in real situations.

\section{Conclusion}

The study results provide evidence of the effectiveness of the educational intervention in improving the knowledge, attitude, practice, and self-efficacy of the caregivers of children with epilepsy. It should be applied in various settings providing care to children with epilepsy, with the provision of its educa- 
tional materials to attendants. The nurses in these settings should regularly assess caregivers' knowledge and practices in order to identify their educational needs.

\section{Conflict of interest}

The authors declare no conflict of interest pertaining to the current study.

\section{Funding}

No funding has been received by authors.

\section{Acknowledgement}

We would like to dedicate the results of this study to the people who suffer from wars and woes, to the mothers who stand over the care of their sick children, to the martyrs and the dead who had tasted the poison of the disease, and to the nurses, the unknown soldiers, who sacrifice, take risks and watch over to provide help, treatment, and care to the sick.

\section{References}

[1] Beghi E. The epidemiology of epilepsy. Neuroepidemiology 2020;54:185-191.

[2] World Health Organization. Mental Health- Epilepsy: a public health imperative 2019 [Accessed January 22, 2020]. Available from: https://who.int/ mental_health/neurology/epilepsy/ report_2019/en/

[3] Shehata G. A Review of Epilepsy Stigma in Egypt. Acta Psychopathologica 2016;2:39-45.

[4] Alshahawy AK, Darwish AH, Shalaby SE, Mawlana W. Prevalence of idiopathic epilepsy among school children in Gharbia Governorate, Egypt. Brain Dev 2018;40:278-286.
[5] Farghaly WM, Abd Elhamed MA, Hassan EM, Soliman WT, Yhia MA, Hamdy NA. Prevalence of childhood and adolescence epilepsy in Upper Egypt (desert areas). Egypt J Neurol Psychiatr Neurosurg 2018;54:1-7.

[6] Seid S, Demilew D, Yimer S, Mihretu A. Prevalence and Associated Factors of Mental Distress among Caregivers of Patients with Epilepsy in Ethiopia: A Cross-Sectional Study Design. Psychiatry J 2018;2018:1-8.

[7] Hansen B, Szaflarski M, Bebin EM, Szaflarski JP. Affiliate stigma and caregiver burden in intractable epilepsy. Epilepsy Behav 2018;85:1-6.

[8] Kampra M, Tzerakis N, Thomsen LLH, Katsarou E, Voudris K, Mastroyianni $\mathrm{SD}$, et al. The challenges that parents of children with epilepsy face: a qualitative study. Epilepsy Behav 2017;71:94-103.

[9] Gutierrez-Angel AM, Martinez-Juarez IE, Hernandez-Vanegas LE, CrailMelendez D. Quality of life and level of burden in primary caregivers of patients with epilepsy: effect of neuropsychiatric comorbidity. Epilepsy Behav 2018;81:12 -17 .

[10] Puka K, Widjaja E, Smith ML. The influence of patient, caregiver, and family factors on symptoms of anxiety and depression in children and adolescents with intractable epilepsy. Epilepsy Behav 2017;67:45-50.

[11] Hussain SA, Ortendahl JD, Bentley TG, Harmon AL, Gupta S, Begley CE, et al. The economic burden of caregiving in epilepsy: An estimate based on a survey of US caregivers. Epilepsia 2020;61:319-329. 
[12] Manju V, Joshi P, Gulati S. A study to assess the knowledge and attitude of parents of children with epilepsy. Indian Journal of Child Health 2015;2:7679.

[13] Berg AT, Kaiser K, Dixon $\square$ Salazar T, Elliot A, McNamara N, Meskis MA, et al. Seizure burden in severe early $\square$ life epilepsy: Perspectives from parents. Epilepsia Open 2019;4:293-301.

[14] Cooper K, Kirkpatrick P, Brand C, Rolfe A, Florida-James S. Discussing sudden unexpected death in epilepsy with children and young people with epilepsy and their parents/carers: a mixed methods systematic review. Seizure 2020:159-167.

[15] Ye X, Ren S, Li X, Wang Z. The mediating role of psychological capital between perceived management commitment and safety behavior. J Safety Res 2020;72:29-40.

[16] Bastani F, Ghasemi E, Negarandeh R, Haghani H. General self-efficacy among family's female caregiver of elderly with Alzheimer's disease. Journal of Hayat 2012;18:27-37.

[17] Kolahi A-A, Abbasi-Kangevari M, Bakhshaei P, Mahvelati-Shamsabadi F, Tonekaboni S-H, Farsar A-R. Knowledge, attitudes, and practices among mothers of children with epilepsy: A study in a teaching hospital. Epilepsy Behav 2017;69:147-152.

[18] Dean A, Sullivan K, Soe M. OpenEpi: open source epidemiologic statistics for public health, Version 3.01. Updated April 6, 2013 [Accessed January 21, 2020]. Available from: https:// www.openepi.com/
[19] Steffen AM, McKibbin C, Zeiss AM, Gallagher-Thompson D, Bandura A. The revised scale for caregiving selfefficacy: Reliability and validity studies. J Gerontol B Psychol Sci Soc Sci 2002;57:74-86.

[20] Jarvie S, Espie CA, Brodie MJ. The development of a questionnaire to assess knowledge of epilepsy: I. General knowledge of epilepsy. Seizure 1993;2:179-185.

[21] Young GB, Derry P, Hutchinson I, John V, Matijevic S, Parrent L, et al. An epilepsy questionnaire study of knowledge and attitudes in Canadian college students. Epilepsia 2002;43:652-658.

[22] Mbuba CK, Abubakar A, Hartley S, Odermatt P, Newton CR, Carter JA. Development and validation of the Kilifi epilepsy beliefs and attitude scale. Epilepsy Behav 2012;24:480-487.

[23] Chomba EN, Haworth A, Atadzhanov M, Mbewe E, Birbeck GL. Zambian health care workers' knowledge, attitudes, beliefs, and practices regarding epilepsy. Epilepsy Behav 2007;10:111119.

[24] El Sharkawy G, Newton C, Hartley S. Attitudes and practices of families and health care personnel toward children with epilepsy in Kilifi, Kenya. Epilepsy Behav 2006;8:201-212.

[25] Mutabazia P. Exploration of knowledge, attitudes and practices among family caregivers towards epileptic patients in a selected district in Rwanda. Int J Sci Basic Appl Res 2014;13:140-146.

[26] Karimi N, Akbarian SA. Knowledge and attitude toward epilepsy of close family members of people with epilep- 
sy in north of Iran. Adv Med 2016;2016:1-6.

[27] Gedefa M, Wolde T, Solomon G. Knowledge, attitudes and practices with respect to epilepsy among preparatory school students in Mekelle city, Ethiopia. International Journal of Collaborative Research on Internal Medicine \& Public Health 2012;4:202-215.

[28] Ezeala-Adikaibe BA, Achor JU, Nwabueze AC, Agomoh AO, Chikani M, Ekenze OS, et al. Knowledge, attitude and practice of epilepsy among community residents in Enugu, South East Nigeria. Seizure 2014;23:882-888.

[29] Neyaz HA, Aboauf HA, Alhejaili ME, Alrehaili MN. Knowledge and attitudes towards epilepsy in Saudi families. J Taibah Univ Med Sci 2017;12:89-95.

[30] Steffen AM, Gallagher-Thompson D, Arenella KM, Au A, Cheng S-T, Crespo $\mathrm{M}$, et al. Validating the revised scale for caregiving self-efficacy: a cross-national review. Gerontologist 2019;59:e325-e342.

[31] Devinsky O. Epilepsy: a patient and family guide. 3rd ed: Demos Medical Publishing; 2008.

[32] Edmonton Epilepsy Association. Epilepsy: A guide for professionals and caregivers: UCB Canada Inc.; 2011. [Accessed December 25, 2019]. Available from: www.edmontonepilepsy.org/

[33] Hamaad WA, Alseraty WHH. Impacts of Seizure Care Simulation Intervention on Mothers' of Epileptic Children Efficiency, Believes, Anxiety and Seizure Care. American Journal of Nursing Research 2019;7:293-300.
[34] Nagan M, Caffarelli M, Donatelli S, Rosman NP. Epilepsy or a seizure disorder? Parental knowledge and misconceptions about terminology. J Pediatr 2017;191:197-203. e195.

[35] Masri A, Aburahma S, Khasawneh A, Qudah AA, Nafi O, Al Momani M, et al. Parental knowledge and attitudes towards epilepsy-A study from Jordan. Seizure 2017;53:75-80.

[36] Kurt ANC. Characteristics of the knowledge and attitudes of parents about epilepsy. Epilepsy Behav 2018;86:153-156.

[37] Gürhopur FDT, Dalgiç AI. The effect of a modular education program for children with epilepsy and their parents on disease management. Epilepsy Behav 2018;78:210-218.

[38] Rani A, Thomas PT. Parental Knowledge, Attitude, and Perception about Epilepsy and Sociocultural Barriers to Treatment. J Epilepsy Res 2019;9:65-75.

[39] Fong CY, Hong SY, Ong LC, Lim WK, Lua PL. Improving awareness, knowledge, and attitude among Malaysian parents of children with epilepsy using an Interactive Animated Epilepsy Education Programme (IAEEP). Epilepsy Behav 2019;94:52-58.

[40] Kaddumukasa M, Nalubwama H, Kaddumukasa MN, Lhatoo S, Sewankambo N, Katabira E, et al. Barriers to epilepsy care in Central Uganda, a qualitative interview and focus group study involving PLWE and their caregivers. BMC Neurol 2019;19:161-170.

[41] Mousavi Dogahe SM, Pasha A, Chehrzad M, AtrkarRoshan Z. The effect of education based on the Health Belief 
Model in mothers about behaviors that prevent febrile seizure in children. International Journal of Biomedicine and Public Health 2018;1:23-29.

[42] Wasilewski A, Serventi J, Ibegbu C, Wychowski T, Burke J, Mohile N. Epilepsy education in gliomas: engaging patients and caregivers to improve care. Support Care Cancer 2020;28:14051409.

[43] Easom L, Wang K, Alston G. Increasing self-efficacy and knowledge in carer training: Hispanic versus Caucasian. Nurs Open 2020;7:180-185.

[44] Tan C-E, Hi M-Y, Azmi NS, Ishak NK. Caregiving Self-efficacy and Knowledge Regarding Patient Positioning Among Malaysian Caregivers of Stroke Patients. Cureus 2020;12:e7390e7401.

[45] Gholami S, Reyhani T, Beiraghi M, Behnam Vashani H. Effect of a supportive educational program on selfefficacy of mothers with epileptic children. Evidence Based Care 2016;6:4956.

[46] Sakanashi S, Fujita K. Development of the empowerment scale for family caregivers of community - dwelling people with dementia in Japan. Jpn J Nurs Sci 2020;17:e12311-e12335. 